\title{
A Study on Consumer Inertia towards E-Wallet usage at Patan City
}

\author{
Anand Patel ${ }^{* 1}$, Dr. Khuman L. Rathod ${ }^{2}$ \\ ${ }^{1}$ Research Scholar, Department of Commerce and Management, Hemchandracharya North Gujarat University, Gujarat, Patan, Gujarat \\ E-mail: anand84maliba@gmail.com \\ ${ }^{2}$ Research Supervisor, Department of Commerce and Management, Hemchandracharya North Gujarat University, Patan, Gujarat
}

\begin{abstract}
Demonetization effect, Government promotion, Merchant acceptance, Effect of COVID-19, availability of internet and smart phones etc. are in favour of adoption of E-wallet in market as payment alternative but still Consumer inertia towards use of E-wallet prevails in India. In spite of many advantages to use E-wallet over traditional payment system, Consumers having hesitation due to concerned factors associated with it. Perceived Risk associated with E-wallet usages are safety, privacy, digital literacy, language, cost, fraud etc. makes impact on intention to use and consumer adoption behaviour. Research aims to examine the major factors concern for consumer's inertia to use of E-wallet. It is an attempt to find out reasons of adoption and impact of demographic variable on concern factors with statistical analysis using SPSS.
\end{abstract}

Keywords - Consumer; E-wallet; Inertia; Concern; Adoption.

\section{Introduction}

E-wallet is electronic wallet which functions similar as physical wallet. E-Wallets are growing exponentially with numbers of users and also in terms of value of transactions day by day in India.

Wallets are generally categories as,

- Open wallets which can only be issued by the banks. They allow to purchase goods and services, cash withdrawal at ATMs and to transfer funds.

- Semi-closed wallets are which have a specific contract with the issuer to accept the payment instruments. They will allow you to buy goods and services or perform financial services at clearly identified merchant locations.

Closed wallets - are accounts issued by a company to a consumer for buying goods and services exclusively from that company. Here a certain amount of money is locked with the company in case of cancellation, return of the order, or gift cards. Popular E-wallets in India are BHIM, Google pay, Pay Tm, Phone pe, Freecharge, MobiQuik, Airtel pay, Amazon pay, Jio money, Oxyzen etc.

\subsection{Acceleration Factors to Adopt E-wallet}

- Demonetization.

- COVID-19 Pandemic.

- Government promotion.

- Benefits over cash mode payment system.

- Acceptance and availability of Merchants acceptance.

Consumer can use E-Wallet to,
- Send/receive money to and from family, friends etc. (receiver is not required to have same E-Wallet account)

- Send money to bank account even overseas.

- Pay utility bills, booking for transport or entertainment, etc.

- Make payments to any of merchants, company, institute etc.

- Pay for government services etc.

Users can use it at all platforms where the facility of payment via E-wallet available within specified limit of amount.

Data of E-wallet user's adoption and growth volume of digital transaction proves that India is moving towards or becoming cashless economy. Smart phones have taken special space in youth who are educated and their technosavvy nature inspires to use E-wallet as payment option. Frequency of using E-wallet is increasing due to acceptance and availability at almost all place where exchange taken place.

\subsection{Dilemma Regarding use of E-wallet}

Technology advancement brought all transaction on one click but when it is about financial matter Indian consumer always look in to all aspects. Besides the advantages of E-wallet following basic questions comes to mind every time when carried out transaction.

- Is my identity and financial data remaining safe with Ewallet service provider?

- Is it safe to use my E-wallet at every available merchant?

- Should I allow E-wallet service provider to access my all information stored in smart phone?

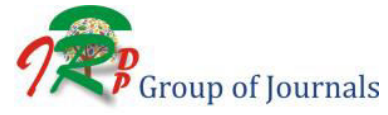


- Is it safe to link my bank account or plastic money card with E-wallet app/s? etc.

\subsection{E-Wallet Working Style}

Almost all E- Wallet gives password and OTP protection to carryout transaction. It is stored information like personal and financial data encrypted. Access to EWallet is via your phone and requires a match between your mobile number and your phone. Any change between the two will require a reactivation of the account before any transaction can be completed.

In addition, E-Wallet requires authentication at every level of transaction. At registration, you will need to set a PIN to protect your account, post this you can set-up more secure biometric authentication via fingerprint scan and face ID.

\section{Literature Review}

As we know that the emergence of E-wallet starts from last few years so the study was carried out with some issues like awareness, usages, method of pattern, perception, adoption, satisfaction, security etc. and still the E-wallets are in era of growth and its still exploring so many more scope of research can possible with different aspects.

Chauhan Pinal (2013) in his research paper "E-Wallet: The Trusted Partner in our Pocket." Found that the security of transaction is beneficial for success as well as it is more crucial to look for security in terms of interoperability and standardization of security and formats. Rouibah (2015) investigated in his paper that poor security, absence of trust dread of disappointment, high charges and poor nature were the significant limitations that influenced e-payments.

In addition, security highlights of web, banking offices, protection and nature of administrations were additionally influencing reception of e-installments. Rathore, H. S. (2016, April) in his research paper "Adoption of Digital Wallet by Consumers" found that adoption of E-wallet due to its advantage of convience and usefulness but major challenges he found are safety and security.

Abhipsa Pal, Sai Dattathrani, Dr. Rahul Dé (March 2017) "Security in Mobile Payments: A Report on User Issues" carried out research on specific E-wallet with BASEL norms and they found serious privacy and security concerns like confidentiality, repudiation management, data transaction integrity, authentication, unauthorized deductions, access \& availability, customer privacy in almost all E-wallets. To gain customer trust they suggested to government, OS \& App vendors to improve or change in features and technology. R Dinakaran (November 30, 2016), reported with heading how safe is your favourite ewallet? Found that the new user's concern for security is increasing. Sushil Punwatkar and Dr. Manoj Verghese (March 2018) "Adaptation of e-Wallet Payment: An Empirical Study on Consumers' Adoption Behavior in Central India" they found that consumers adoption behavior is rise day by day and becoming most likely used mode of online payment. They also found that perceived security factor is require prime concern compare to other factors. Secondly technical knowhow factor is not affecting the youth and followed by intention to use factor is mostly affect adoption behavior of consumer.

Swapnil Undale, Ashish Kulkarni and Harshali Patil (July 2020) in their research paper "Perceived E-Wallet security: impact of COVID-19 pandemic" found that rise in e-wallet users in Covid-19 pandemic and it is forceful no willful adoption but among them middle income group and female are more concerned for security.

\subsection{Research Gap}

The gap of the work is restricted to the consumer's experience and perceived risk associated with utility of Ewallets. This study has attempted to cover the gap of customers concern and also discussed about impact of demographical variables on it.

\section{Research Methodology}

\subsection{Research Design}

Descriptive research design is used for this research paper. Descriptive research is the part of management research where the characteristics of the variable are used for the study.

\subsection{Objective of the Study}

- To study factors affecting consumers inertia to use Ewallet.

- To analyse which factor/s drive consumer to adopt Ewallet.

- To analyse concern factors and perceived risk associate with use of E-wallet.

- To study Demographic variable impact on consumer's concern for E-wallet usage.

\subsection{Limitation of the Study}

- Study carried out in small city of Patan situated in Gujarat so generalisation of result may differ.

- Time taken to carryout research is a limited to 8

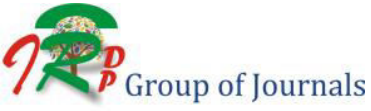


months.

- Technological advancement and improvement may vary User's concern in future.

\subsection{Research Hypothesis}

H01: There is no significant relationship between demographic factors and concern factors regarding use of E-wallet.

\subsection{Data Collection}

Survey is carried out to collect primary data with structured questionnaire and secondary data is collected online (websites) and offline (books, magazine, newspapers etc.)

\subsection{Sample Size \& Sampling Method}

Researcher approach to 200 respondents with Simple random technique and out of them 152 respondents gave responses.

\section{Data Analysis}

MS excel and SPSS are used for data analysis. In this research work, reliability, demographic frequency, descriptive frequency and anova are used.

Table 1. Reliability Statistics

\begin{tabular}{|c|c|}
\hline Cronbach's Alpha & N of Items \\
\hline .847 & 17 \\
\hline
\end{tabular}

Source: SPSS from primary data

Table 2. Frequency statistics

\begin{tabular}{|c|c|c|c|}
\hline \multicolumn{2}{|c|}{ Demographic variables } & \multirow{2}{*}{$\begin{array}{l}\text { Frequency } \\
104\end{array}$} & \multirow{2}{*}{$\begin{array}{l}\text { Percentage } \\
68.42\end{array}$} \\
\hline$=$ & $1=$ Male & & \\
\hline 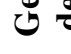 & $2=$ Female & 48 & 31.58 \\
\hline \multirow{5}{*}{$\underset{⿱ 亠 乂}{*}$} & $1=$ Below20 & 19 & 12.50 \\
\hline & $2=21$ to 30 & 55 & 36.18 \\
\hline & $3=31$ to 40 & 61 & 40.13 \\
\hline & $4=41$ to 50 & 17 & 11.18 \\
\hline & $5=$ Above 51 & 0 & 0 \\
\hline \multirow{4}{*}{ 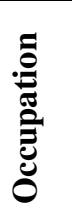 } & $1=$ Student & 49 & 32.24 \\
\hline & $2=$ Service & 39 & 25.66 \\
\hline & $3=$ Agriculture & 11 & 7.24 \\
\hline & 4=Housewife & 12 & 7.89 \\
\hline
\end{tabular}

\begin{tabular}{|c|c|c|c|}
\hline & 5=Professional & 41 & 26.97 \\
\hline \multirow{5}{*}{ 氕 } & $1=\mathrm{Up}$ to hsc & 47 & 30.92 \\
\hline & 2=Diploma & 22 & 14.47 \\
\hline & $3=$ Graduate & 62 & 40.79 \\
\hline & $4=$ Post graduate & 20 & 13.16 \\
\hline & $5=$ Other & 1 & 0.66 \\
\hline \multirow{6}{*}{ 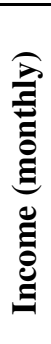 } & $1=\mathrm{Up}$ to 10000 & 41 & 26.97 \\
\hline & $2=10001$ to 20000 & 23 & 15.13 \\
\hline & $3=20001$ to 30000 & 32 & 21.05 \\
\hline & $4=31001$ to 40000 & 23 & 15.13 \\
\hline & $5=40001$ to 50000 & 22 & 14.47 \\
\hline & $6=$ More to 50001 & 11 & 7.24 \\
\hline
\end{tabular}

Source: SPSS from primary data

Table 3. Descriptive Statistics Frequency of use of Ewallet

\begin{tabular}{|l|l|l|l|}
\hline & N & Mean & $\begin{array}{c}\text { Std. } \\
\text { Deviation }\end{array}$ \\
\hline Once in a month & 152 & .50 & .502 \\
\hline Once in a week & 152 & .41 & .494 \\
\hline Every day & 152 & .08 & .271 \\
\hline Once in a year & 152 & .01 & .114 \\
\hline Valid N (listwise) & 152 & & \\
\hline
\end{tabular}

Source: SPSS from primary data

Table 4. Reasons for adoption of E-wallet

\begin{tabular}{|l|c|l|l|}
\hline & N & Mean & $\begin{array}{c}\text { Std. } \\
\text { Deviation }\end{array}$ \\
\hline covid-19 pandemic & 152 & .61 & .490 \\
\hline Govt. promotion & 152 & .55 & .500 \\
\hline willful adoption & 152 & .40 & .492 \\
\hline $\begin{array}{l}\text { Merchants } \\
\text { acceptance/ availability }\end{array}$ & 152 & .38 & .486 \\
\hline Demonetization & 152 & .25 & .434 \\
\hline Other & 152 & .18 & .389 \\
\hline Valid N (listwise) & 152 & & \\
\hline
\end{tabular}

Source: SPSS from primary data

ANOVA test : As per above table no 4.4 There is significant difference between demographic variable and factors concern for consumer regarding use of E-wallet so the researcher reject Hol Null hypothesis. Also we can see 
there is close relation of concern factors with the level of

Education.

Table 5. ANOVA analysis

\begin{tabular}{|l|c|c|c|c|c|c|c|l|l|l|}
\hline \multirow{2}{*}{$\begin{array}{c}\text { Factors concern for consumer } \\
\text { while using E-wallet }\end{array}$} & GENDER & \multicolumn{2}{c|}{ AGE } & \multicolumn{2}{c|}{ OCCUPATION } & \multicolumn{2}{c|}{ EDUCATION } & \multicolumn{2}{c|}{ INCOME } \\
\cline { 2 - 12 } & F & sig. & F & sig. & F & sig. & \multicolumn{1}{c|}{ F } & sig. & F & sig. \\
\hline Theft of identity/ Privacy & 2.02 & 0.16 & 0.714 & 0.545 & 1.71 & 0.15 & 6.82 & 0 & 1.27 & 0.28 \\
\hline Poor Internet connectivity & 4.15 & 0.04 & 0.451 & 0.717 & 1.53 & 0.2 & 2.95 & 0.02 & 0.63 & 0.68 \\
\hline Trusted Merchant acceptance & 0.28 & 0.6 & 3.503 & 0.017 & 0.97 & 0.43 & 2.7 & 0.03 & 0.51 & 0.77 \\
\hline Costs/ Hidden charges & 1.22 & 0.27 & 0.65 & 0.584 & 2.36 & 0.06 & 4.09 & 0 & 0.88 & 0.49 \\
\hline Lack of technology knowhow & 4.15 & 0.04 & 2.724 & 0.046 & 2.51 & 0.04 & 3.7 & 0.01 & 2.55 & 0.03 \\
\hline Hacking of financial transaction & 3.24 & 0.07 & 4.72 & 0.004 & 0.39 & 0.82 & 4.8 & 0 & 0.16 & 0.98 \\
\hline Language & 2.86 & 0.09 & 0.819 & 0.485 & 2.69 & 0.03 & 4.05 & 0 & 2.56 & 0.03 \\
\hline Literacy & 4.32 & 0.04 & 1.859 & 0.139 & 2.82 & 0.03 & 1.67 & 0.16 & 4.6 & 0 \\
\hline Terms and conditions & 4.01 & 0.05 & 5.745 & 0.001 & 5.53 & 0 & 2.59 & 0.04 & 1.57 & 0.17 \\
\hline
\end{tabular}

Source: SPSS from primary data

\section{Findings}

- Majority of the respondents are male $(61 \%)$, students $(33 \%)$, graduate $(41 \%)$, having age between 31 to 40 years (41\%) and income below Rs. 10000/- per month.

- Majority of consumers use either once in a month (mean 0.50) or once in a week (mean 0.41).

- Consumers adopt E-wallet with certain reasons and from that major reason is Covid-19 pandemic (mean 0.61 ) and government promotion (mean 0.55) followed by willful adoption (mean 0.40 ), merchants acceptance or availability (mean0.38) and Demonetization (mean0.25).

- Consumer's concern factors regarding use of E-wallet is having association with all demographic variables but the close association is with Education qualification followed by gender, age, occupation, and income level.

\section{Conclusion}

- Consumer's adoption of E-wallet is pushed by last few years' circumstances and the major reason is lockdown given by government in Covid-19 pandemic. Indian government play crucial role in promotion of digital India by providing awareness campaign, training, workshops, schemes, launching of BHIM application, providing infrastructures, support and assistance where ever needed which gain trust of consumer to willful adoption and use E-wallet. Impact of Demonetization on adoption of E-wallet is for shorter period of time.

- News and cases regarding fraud, cybercrime, security, and privacy make consumer to concern for the risk associated with its usage. Consumer becomes anxious about personal and financial data which may get disclosed, theft or misused. Service providers gives protection of the data and layers of authentication but still there are some hackers comes with decoding system who hunt consumer on this front.

- Consumers with higher education qualification are having more concern for factors like security breach, privacy and risk associated with usage of E-wallet. So education qualification, technology knowhow, digital literacy and terms and conditions related to E-wallet usage must consider gaining customers trust.

\subsection{Suggestions}

- RBI government and service providers should improve or add-on the layers of protection in E-wallets so customer can use it without hesitation Example like Free Charge launches India's first e-wallet protection plan.

- Customers don't have adequate awareness and digital literacy about safe usage of digital payment system so they are equally responsible for not taking care of privacy and security so on consumers side they have to take some precautions and being aware of safe and secure usage of E-wallet is also needed to focus.

\section{References}

[1] Swapnil Undale, Ashish Kulkarni and Harshali Patil;"E-Wallet security: impact of COVID- 19 pandemic"; July 2020. Retrieved from https: // www. emerald.com / insight / 0973- 1954. htm on 12.03.2021. 
[2] Abhipsa Pal, Sai Dattathrani, Dr. Rahul Dé (march 2017) " Security in Mobile Payments: A Report on User Issues", IIM banglore; retrieve from https:// www.iimb.ac.in/ sites/default/files/inline-files/ iimb csitm- security- issues- in- mobile- payment. pdf on 10.03.2021.

[3] Rathore, H. S. (2016, April) Adoption of Digital Wallet by Consumers. BVIMSR's Journal of Management Research, VIII (1), 69-76.

[4] Chauhan, P. (2013) E-wallet: The trusted partner in our pocket. International journal for research in management and pharmacy, Vol 2, issue 4, 12-19.

[5] Sushil Punwatkar, Dr. Manoj Verghese (march 2018) "Adaptation of e-Wallet Payment: An Empirical Study on Consumers' Adoption Behavior in Central India" International Journal of Advanced in Management, Technology and Engineering Sciences, Volume 8, Issue III, MARCH/2018.

[6] https:// www.e- wallet.ae/en/faq/ faq-about- wallet.jsp retrieve on 10.03.2021.

[7] https:// www.livemint.com/ money/ personal- finance /should-you-be-held-responsible-for-preventing-an-ewallet-fraud-11575268929129.html retrieve on 11.03.2021.

[8] https://www.varindia.com/news/freecharge - launchesindia- first- ewallet- protection-plan retrieve on 12.03.2021.

[9] https://www.thehindubusinessline.com/specials/techno phile / how-safe- is - your - favourite- ewallet / article9 402284. ece retrieve on 14.03.2021. 